\title{
Single-Atom Catalysis: A Practically Viable Technology?
}

\author{
Rosaria Ciriminna, ${ }^{[a]}$ Mina Ghahremani, ${ }^{[a][b]}$ Babak Karimi, ${ }^{*[b]}$ Mario Pagliaro, ${ }^{*[a]}$ Rafael Luque ${ }^{*[c, ~ d]}$
}

\begin{abstract}
Recent advances in single-atom catalysis resulted in readily accessible materials whose application in most catalytic reactions mediated by conventional nanoparticle-based catalysts often results in higher activity and selectivity. Can we expect catalysis by atomically dispersed atoms to find practical applications? Which are the hurdles to be overcome prior to widespread uptake of atomically dispersed metals in industrial synthetic processes and in hydrogen fuel cells?
\end{abstract}

Keywords: Single-atom catalysis; heterogeneous catalysis; chemical innovation; low atomicity

\section{Introduction}

Single-atom catalysis (SAC) became a well-established field of contemporary chemical research in less than a decade since the introduction of the term by Zhang and co-workers in 2011, when the team based in China reported that single Pt atoms supported on FeOx are both active and markedly stable for $\mathrm{CO}$ oxidation ${ }^{[1]}$. Eight years before, Flytzani-Stephanopoulos and co-workers in the US had discovered that nonmetallic gold or platinum species strongly associated with surface cerium-oxygen groups in ceria, and not Au or Pt nanoparticles (NPs), were actually responsible for the activity observed in the water-gas shift reaction. ${ }^{[2]}$

Comprehensive review ${ }^{[3]}$ and perspective ${ }^{[4]}$ articles have been devoted to the topic, including entire themed issues ${ }^{[5]}$ and reviews focusing on applications of SAC catalysts in synthetic organic chemistry. ${ }^{[6]}$ Readers are kindly referred to the aforementioned studies, as well as to the recent accounts of Zhang ${ }^{[7]}$ and PerezRamire ${ }^{[8]}$ and co-workers, to understand how single atoms get stabilized on various supports, and the unique features dictating the performance of SAC relative to conventional NP catalysts. From a structural viewpoint, contemporary surface science has been and will continue to be instrumental to unravel the unique structural features of these materials. ${ }^{[9]}$

In general, metal atoms in heterogeneous single-atom catalysts are bound to the support surface through heteroatoms such as oxygen and nitrogen or defective metal active sites. Successful

[a] Dr. Rosaria Ciriminna, Dr. M. Pagliaro

Istituto per lo Studio dei Materiali Nanostrutturati, CNR via U. La Malfa 153

90146 Palermo (Italy)

E-mail: mario.pagliaro@cnr.it; Web: www.qualitas1998.net

[b] Mrs Mina Ghahremani, Prof. B. Karimi

Department of Chemistry, Institute for Advanced Studies in Basic

Sciences (IASBS)

PO-Box 45195-1159

Gavazang, Zanjan 45137-6731 (Iran)

E-mail: karimi@iasbs.ac.ir

[c] Prof. R. Luque

Departamento de Química Orgánica

Universidad de Cordoba

Campus de Rabanales, Ctra. Nnal. IV-A, Km. 396

E-14014 Cordoba (Spain)

E-mail: rafael.luque@uco.es

[d] Prof. R. Luque

Peoples Friendship University of Russia (RUDN University)

6 Miklukho-Maklaya Str., 117198, Moscow, Russia synthetic approaches include single atom metal anchoring, ${ }^{[10]}$ alloying $^{[11]}$ or atomic layer deposition. ${ }^{[12]}$ Selected exemplary applications of the catalysts thereby obtained include $\mathrm{Pt} / \mathrm{m}-\mathrm{Al}_{2} \mathrm{O}_{3}$ and $\mathrm{Pt} / \mathrm{CeO}_{2}$ for selective hydrogenation and $\mathrm{CO}$ oxidation, ${ }^{[13]}$ $\mathrm{Pt} / \mathrm{graphene}$ in electro-oxidation of methanol, ${ }^{[14]}$ gold clusters "of low atomicity" of exceptional catalytic activity in the oxidation of thiophenol with oxygen, ${ }^{[15]}$ and non-precious metals such as $\mathrm{Fe}$, $\mathrm{Cu}, \mathrm{Cr}$, $\mathrm{Co}$, and $\mathrm{Ni}$ on nitrogen-containing carbon in alcohol oxidative dehydrogenation. ${ }^{[16]}$

This study critically focuses on the practical application of singleatom catalysis. Can we expect SAC to become a technically and economically viable technology suitable to find applications in the chemical industry and in commercial hydrogen fuel cells? Which are, if any, the hurdles to be overcome for single-atom catalysis prior to become ubiquitous?

Starting from three selected examples, this study provides an answer to these questions and offers a critical perspective in the context of the emerging solar economy in which useful substances and energy will originate, respectively, from biological resources and from solar energy. ${ }^{[17]}$

\section{Potentially disruptive technologies}

Following Christensen, an innovation is called "disruptive" as it eventually displaces established market-leading products and solutions. ${ }^{[18]}$ The three examples of SAC discussed below hold a disrupting innovation potential in synthetic organic chemistry, in the production of solar hydrogen from water, and in electricity generation in hydrogen fuel cells.

\subsection{Synthetic organic chemistry}

Recently Tao and co-workers in China and in the US reported how a $\mathrm{TiO}_{2}$-based catalyst anchoring singly dispersed $\mathrm{Pd}$ atoms $\left(\mathrm{Pd} 1 / \mathrm{TiO}_{2}\right)$ is highly selective and highly active for more than 10 Sonogashira $\mathrm{C}-\mathrm{C}$ coupling reactions $\left(\mathrm{R} \equiv \mathrm{CH}+\mathrm{R}^{\prime} \mathrm{X} \rightarrow \mathrm{R} \equiv \mathrm{R}^{\prime} ; \mathrm{X}\right.$ $=\mathrm{Br}, \mathrm{I} ; \mathrm{R}^{\prime}=$ aryl or vinyl) carried out on 1-2 mmol scale. ${ }^{[19]}$
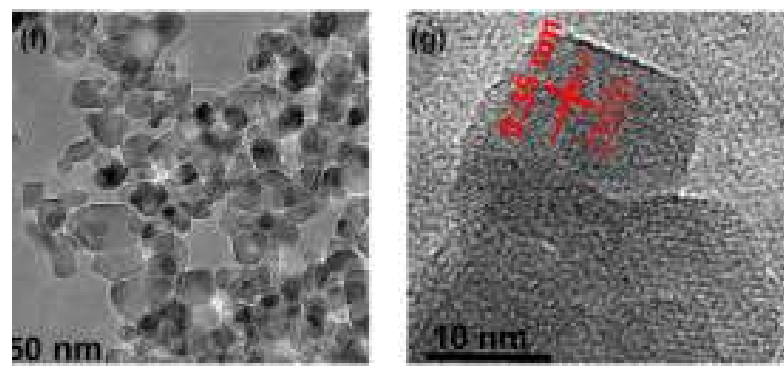

Figure 1. TEM images of of $0.20 \mathrm{wt} \% \mathrm{Pd}_{1} / \mathrm{TiO}_{2}$ catalyst particles at different high-resolution. [Reproduced with permission from Ref.19].

The catalyst (Figure 1) exhibits high activity and selectivity for $\mathrm{C}-\mathrm{C}$ couplings between aryl halide $(\mathrm{X}=\mathrm{I}$ and $\mathrm{Br})$ and different 
terminal alkynes, with the usual lower activity towards chlorobenzene (the $\mathrm{C}-\mathrm{Cl}$ bond is much stronger than $\mathrm{C}-\mathrm{Br}$ and $\mathrm{C}$ I bonds) observed with NP catalysts.

In further detail, coupling between iodobenzene and phenylacetylene on $0.20 \mathrm{wt} \% \mathrm{Pd}_{1} / \mathrm{TiO}_{2}$ exhibits a turnover rate of 51 diphenylacetylene molecules per anchored $\mathrm{Pd}$ atom per minute at $60{ }^{\circ} \mathrm{C}$, with a low apparent activation barrier for the same $\mathrm{C}-\mathrm{C}$ coupling of $28.9 \mathrm{~kJ} / \mathrm{mol}$, and straightforward catalyst separation. For comparison, the activation barrier of $\mathrm{C}-\mathrm{C}$ coupling of phenylacetylene and iodobenzene catalyzed by molecular catalyst $\mathrm{Pd}\left(\mathrm{PPh}_{3}\right)_{2} \mathrm{Cl}_{2}$ in solution is $51.7 \mathrm{~kJ} / \mathrm{mol}$.

Calculations suggest that the single $\mathrm{Pd}$ atom bonded to surface lattice oxygen atoms of $\mathrm{TiO}_{2}$ acts to dissociatively chemisorb iodobenzene to generate an intermediate phenyl, which then couples with phenylacetylenyl bound to a surface oxygen atom. This coupling of phenyl adsorbed on $\mathrm{Pd}_{1}$ and phenylacetylenyl bound to $\mathrm{O}_{\mathrm{ad}}$ of $\mathrm{TiO}_{2}$ forms the diphenylacetylene product molecule. ${ }^{[19]}$

epeated catalytic tests showing stable catalytic activity, though on the usual 1-2 mmol scale of most academic research papers, confirmed the durability of $\mathrm{Pd}_{1} / \mathrm{TiO}_{2}$.

Along similar lines, Perez-Ramirez and co-workers elegantly reported how $\mathrm{Pd}$ atoms anchored on exfoliated graphitic carbon nitride ( $\mathrm{Pd}-\mathrm{ECN}$ ) capture the advantages of both homogeneous and heterogeneous catalysts in C-C couplings (Suzuki-Miyaura), with an additional robust stability under flow conditions. ${ }^{[20]}$

This material surpasses the performance of state-of-the-art homogeneous catalysts and conventional heterogeneous catalysts based on nanoparticles or grafted molecular complexes, without evidencing metal leaching or aggregation upon reaction completion. The authors nicely explained the enhanced properties with studies at the molecular level, showing how carbon nitride can enable an adaptive coordination to palladium, participating at the same time in the adsorption, stabilization and activation of substrates and intermediates. The support provides a ligand-like stabilization which minimized catalyst deactivation even under continuous flow conditions. ${ }^{[20]}$

\subsection{Solar hydrogen from water}

In the emerging solar economy in which sun, wind and water will be the renewable energy sources for all end energy uses, ${ }^{[21]}$ renewable hydrogen generated splitting water via both concentrated solar power and electrolysis will emerge as key clean fuel. ${ }^{[22]}$

Hydrogen refueling stations installed across the world will all make use of water electrolysis to generate hydrogen gas on site. The gas is then compressed at the required 350 or 700 bar at which $\mathrm{H}_{2}$ is dispensed at hydrogen fuel cell cars, buses and trucks

Today, most water electrolysers use alkaline water electrolysis relying on nickel to mediate both the hydrogen evolution reaction at the cathode and oxygen evolution reaction at the anode (nickelplated mild steel). ${ }^{[23]}$ Therefore, the production of solar hydrogen at the large scale needed by massive deployment of hydrogen fuel cell electric vehicle (FCEVs) will greatly benefit from advances in the electrode catalytic performance (lower voltage, and reduced energy demand). ${ }^{[24]}$
In 2015, a joint team of scholars in China and in the US led by Tour reported that single cobalt atoms at the surface of graphene doped with nitrogen efficiently mediate the hydrogen separation from water. ${ }^{[25]}$ The resulting electrocatalyst was found to be robust and highly active in both basic and acidic conditions, with very low over-potential $(30 \mathrm{mV})$.

TEM analysis shows cobalt atoms widely dispersed throughout the graphene sheets (Figure 2). The $\mathrm{N}$-doped graphene molecular sheets have a dual important role, enabling high electron mobility and strong metal-support interaction. Thanks to strong coordination between the $\mathrm{Co}$ and $\mathrm{N}$ atoms, the electrocatalyst shows a negligible decrease in activity after 10 hours of accelerated degradation studies in both acid and base conditions. In detail, the cathodic polarization curves obtained after 1,000 continuous cyclic voltammograms showed a negligible decrease in current density compared with to initial values, whereas extensive characterization of the catalyst suggests that cycling operation did not change the atomic Co dispersion or the chemical states of Co and N. ${ }^{[25]}$

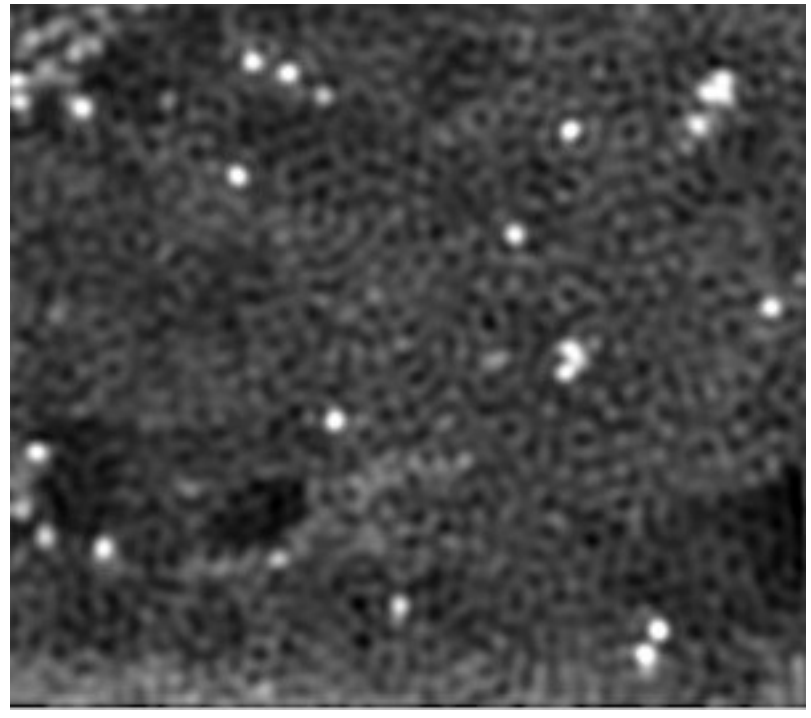

Figure 2. TEM of Co on N-doped graphene. White spots correspond to Co atoms. [Photo courtesy of Professor James M. Tour, Rice University]

Finally, the catalyst synthetic protocol is simple and highly reproducible involving only sonication of graphene oxide (GO) in the presence of $\mathrm{CoCl}_{2} \cdot 6 \mathrm{H}_{2} \mathrm{O}$ dissolved in water (weight ratio $\mathrm{GO} / \mathrm{Co}=135: 1$ ), followed by freeze-drying to minimize re-stacking of the $\mathrm{GO}$ sheets, and calcination of the dried sample under an $\mathrm{Ar} / \mathrm{NH}_{3}$ atmosphere at $750^{\circ} \mathrm{C} .{ }^{[25]}$

\subsection{Low platinum and platinum-free fuel cells}

Today's hydrogen fuel cell cars contain on average about the same amount of Pt contained in the catalytic converters of diesel vehicles (3-7 grams, depending on size and power of the automobile). ${ }^{[26]}$ To put progress into perspective, thanks also to 
a new alloyed platinum catalyst now dispersed onto a solid core type carbon support, the new 'Mirai' $\mathrm{H}_{2}$ fuel cell car commercialized in 2015 by a Japan's carmaker contains less than half the amount of Pt contained in the $2008 \mathrm{FCV}$ model of the same manufacturer, with a $>2$ larger volumetric power density than the previous version ( $3.1 \mathrm{~kW} / \mathrm{L}$ vs. $1.4 \mathrm{~kW} / \mathrm{L}) .^{[27]}$

In 2016, Nakanishi, Hashimoto and co-workers achieved a tenfold reduction in the amount of $\mathrm{Pt}$ needed in the electrocatalytic hydrogen oxidation in polymer electrolyte membrane (PEM) fuel cell by replacing commercial $20 \mathrm{wt} \% \mathrm{Pt} / \mathrm{C}$ with a $2.8 \mathrm{wt} \%$ single atom $\mathrm{Pt}$ catalyst comprised of covalent triazine framework ( $\left.\mathrm{Pt}^{1} / \mathrm{CTF}\right)$ with atomically dispersed $\mathrm{Pt}$ atoms. ${ }^{[28]}$

The electrocatalytic activity of the resulting electrode in hydrogen oxidation reaction proceeds on single $\mathrm{Pt}$ atoms and requires almost no activation energy. Hence, the activity was dramatically higher when compared to that of commercial $\mathrm{Pt} / \mathrm{C}$.

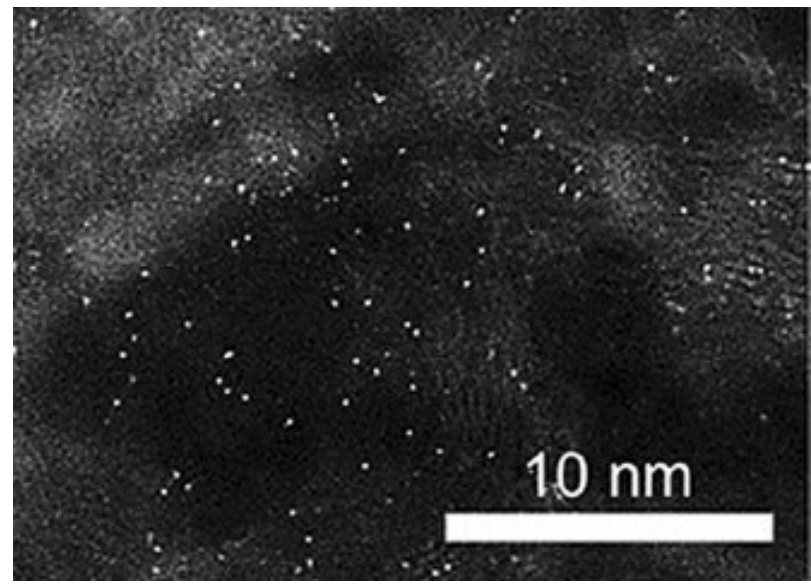

Figure 3. High-angle annular dark-field scanning transmission electron microscopy photograph of covalent triazine framework functionalized with $\mathrm{Pt}$ developed by Nakanishi and co-workers. [Reproduced with permission from Ref.27].

In detail, the maximum power density of the membrane electrode assembly (MEA, an assembled stack of proton exchange membranes, catalyst and flat plate electrode used in PEM fuel cells) using the single-atom Pt catalyst was $487 \mathrm{~mW} / \mathrm{cm}^{2}$ at 1.2 $\mathrm{A} / \mathrm{cm}^{2}$, a value nearly identical to that of the same MEA using the conventional $\mathrm{Pt} / \mathrm{C}$ nanoparticle catalyst $\left(462 \mathrm{~mW} / \mathrm{cm}^{2}\right.$ at 1.0 $\mathrm{A} / \mathrm{cm}^{2}$ ) containing approximately 5 times more platinum. ${ }^{[28]}$

As extensively shown lately by Artz, covalent triazine frameworks are ideally suited as supports for catalytic species due to their high chemical and thermal stability coupled to easily tunable functionality to support catalytically active sites. ${ }^{[29]}$

\section{An industrially viable technology?}

According to Polshettiwar, SACs would be "still far away from the commercialization, as technologies require stable single and pseudo-single atom catalysts with high metal loadings, which is still a challenge". ${ }^{30]}$ In other words, the first main hurdle to be overcome prior to assist to the uptake of SAC in industry is the increase in the catalyst loading (i.e., high coverage of single atoms) so as to enable the use of acceptable catalyst amounts in existing industrial synthetic plants, in water electrolyser or fuel cell stacks.

In collaboration with Chinese scholars, Beller's team has lately introduced a single-atom catalyst comprised of single Pt atoms dispersed on $\mathrm{Al}_{2} \mathrm{O}_{3}$ nanorods of excellent selective activity and stability in olefin hydrosilylation, namely the key process to prepare the silicone precursors. ${ }^{[31]}$

Asked to comment on the industrial applicability of SAC, Professor Beller remarked that: "I believe the topic of SAC is apart from being scientifically interesting also of significant importance for industrial processes. Personally, I do not know about any current industrial realization but in some industrial processes the 'real' structure of the catalyst is still unknown and due to the recent progress in analytics such SAC structures could not be detected in the past. Due to the intrinsic advantages regarding activity in general much more attention will be paid to SACs in the future. Regarding our process we are continuing to work in that direction, especially to replace $\mathrm{Pt}$ by other metals and to keep the activity". ${ }^{32]}$

In full analogy to heterogeneously catalyzed reactions mediated by supported nanoparticles, ${ }^{[33]}$ the support plays a key role also in single-atom catalysis. For example, the high selective activity of single $\mathrm{Rh}$ atoms supported on $\mathrm{ZnO}$ nanowires in the hydroformylation of olefins in batch $(2.5 \mathrm{mmol}$ substrate under $\mathrm{CO} / \mathrm{H}_{2}$ pressure of $0.8 \mathrm{MPa}$ at $\left.100{ }^{\circ} \mathrm{C}\right)^{[34]}$ fully comparable (TON $\approx 40,000$ ) to that of the homogeneous Wilkinson's catalyst $\left[\mathrm{RhCl}\left(\mathrm{PPh}_{3}\right)_{3}\right]$ is due to the $\mathrm{ZnO}$ oxide surface in $\mathrm{Rh}_{1} / \mathrm{ZnO}-\mathrm{nw}$ acting "as robust ligands that tune the electronic structure of isolated Rh centres". ${ }^{[7]}$

When a new catalyst suitable for an industrial synthetic process is introduced, industry will generally opt for one of two options. ${ }^{[35]}$ If the economic advantages offered by the new catalysts are significant (disruptive technology), ${ }^{[18]}$ a completely new plant will be built whose economics outperform the older process/plant by such an extent to make the investment economically sound. If, instead, the economic advantages offered by the new catalyst do not lead to a return on investment (ROI) large enough to justify a switch to a new chemical plant or process, industry will use the new catalyst if it can directly replace the catalyst currently employed in the existing process (plant) or fuel cell stack.

Be it synthetic organic chemistry, water electrolysis or fuel cell energy conversion via reaction at the electrodes of hydrogen and oxygen, these are advanced and highly reliable chemical technologies whose level of reliability will need to be retained when adopting SAC. Otherwise, industry will not switch to new technologies. For instance, water electrolysis is a highly reliable technology. A sugar company in South Africa still uses today a large electrolyser (capacity: $360 \mathrm{Nm}^{3} \mathrm{H}_{2}$ /hour) for the production of furfuryl alcohol that was installed at its premises in 1983 during a plant expansion. ${ }^{[36]}$ The electrolyser runs at full capacity 24 hours a day, requiring no significant maintenance until the planned routine overhaul. 
A catalyst such as the single atom Co-N-doped graphene developed by Tour and co-workers, ${ }^{[25]}$ for example, is ideally suited to replace the existing $\mathrm{Ni}$ cathodes in electrolysers, enabling operation at lower voltage and thus saving energy, while not requiring the electrolyser company the complete redesign of the electrolysis equipment.

Introduced in 2015 and obtained starting from graphene oxide (GO) synthesized from graphite flakes ( $150 \mu \mathrm{m}$ flakes) using an improved of the Hummer's method (well known for its high pollution potential and poor atom economy), the electrocatalyst above for hydrogen evolution reaction so far has not been commercialized, despite its impressive chemical and physical stability. ${ }^{[25]}$

Furthermore, due to the very low content of Co, the Co-containing precursor solution forming a stable suspension similar to the pure GO solution could be easily coated on conductive substrates via drop-casting onto a carbon fiber paper (CFP) in a defined area $\left(1 \times 1 \mathrm{~cm}^{2}\right)$ using directly the Co-NG on CFP as a working electrode for hydrogen evolution reaction, with the electrocatalyst on CFP delivering a remarkable stable current during the testing period. ${ }^{[25]}$

Besides being suitable for laboratory scale material syntheses only, the Hummer's method produces reduced graphene oxide (RGO) irregular flakes of small size in which, for instance, the electrical conductivity and charge carrier mobility are reduced due to disruption of the $2 \mathrm{D} \pi$-conjugation of the RGO sheet electronic structure.

In 2014, however, Coleman and co-workers at a British chemical company introduced a new surfactant-assisted graphite exfoliation method overcoming the limits of the Hummer's synthesis, affording large amounts of defect-free few-layer graphene. ${ }^{[37]}$ Shortly afterwards, high quality graphene at affordable price became available on the marketplace. ${ }^{[38]}$ This, we argue, is the graphene form that will be used to support the first commercial single-atom electrocatalyst for water electrolysis.

Asked to comment whether heterogeneous single metal atom catalysts will be commercialized soon, Professor Tour responded "the key will be how many single atom catalysts can be packed into the small space before they will agglomerate to nanoparticles and thereby be less active. So the volume requirements will be a question". ${ }^{[39]}$

\section{Outlook and Perspectives}

In a series of fundamental works started in 2012, Ananikov and co-workers have shown how homogeneous and heterogeneous catalysts are both involved in transition metal catalysis, disclosing that commercially available samples of $\mathrm{Pd}_{2}(\mathrm{dba})_{3}$ readily contain up to $40 \%$ of $\mathrm{Pd}$ nanoparticles which during catalysis in crosscoupling reactions progressively decompose to form $\mathrm{Pd}$ complexes and clusters in solution, giving place to a "cocktail" of multiple catalytic species in solution (Figure 4). ${ }^{[40]}$
Single-atom catalysis can be seen as the ultimate consequence of applying the atom economy concept to heterogeneous catalysis, with full utilization of all metal atoms. In brief, practical application of SAC requires supports tightly binding a large number of single-atom species accessible to reactants at the outer surface, retaining their high selective activity for prolonged reaction times. Chemical and physical robustness, in their turn, depend on the intrinsic stability of the support and on the chemical interaction of the single atoms with the supporting surface.

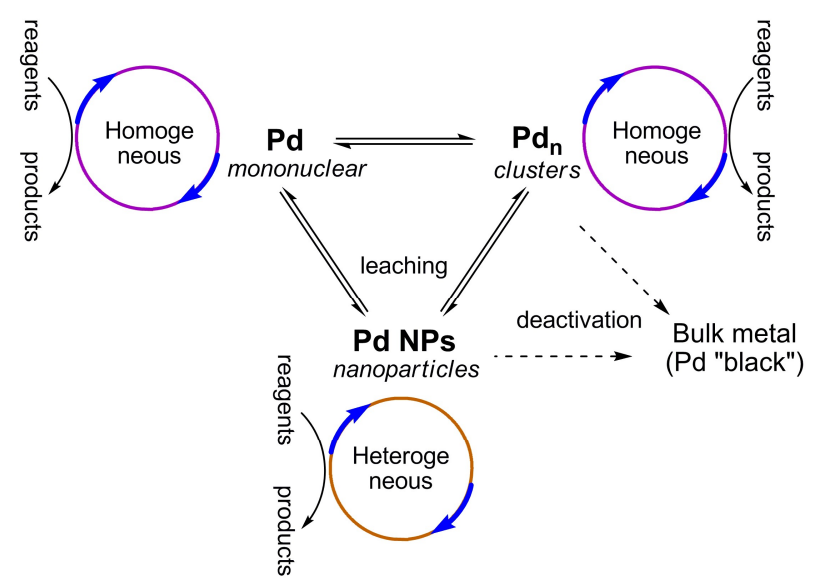

Figure 4. $\mathrm{Pd}$ catalysis of cross-coupling reactions using homogeneous $\mathrm{Pd}$ complexes involves a cocktail of catalytic species in solution. [Image courtesy of Prof. Valentine P. Ananikov, Russian Academy of the Sciences].

Once single-atom catalysts of enough activity and prolonged stability will be developed, industrial uptake will be rapid both for chemical productions (especially in fine chemical and pharmaceutical productions) and for hydrogen fuel cells and water electrolysers currently experiencing dramatic growth. ${ }^{[41]}$

\section{Acknowledgements}

This article is dedicated to Professor Matthias Beller, Universität Rostock, whose fundamental studies in catalysis science including bridging heterogeneous and homogeneous catalysis via single-atom catalysis, have greatly contributed to the progress of catalysis technology. We thank Professor James. M. Tour, Rice University, for helpful correspondence. M.P. is indebted to Professor Valentine P. Ananikov, Russian Academy of the Sciences, for a memorable lecture on heterogeneous catalysis held in Sicily on the occasion of FineCat 2016. The manuscript was prepared with support from RUDN University Program 5-100.

Keywords: single atom catalysis - heterogeneous catalysis • atom economy $\cdot$ green chemistry 


\section{References}

[1] A. Qiao Wang, X. Yang, F. A. Lawrence, J. Zheng, Y. Cui, J. Liu, L. Jun, T. Zhang, Nat. Chem. 2011, 3, 634-641.

[2] Q. Fu, H. Saltsburg, M. Flytzani-Stephanopoulos, Science 2003, 301, 935-938.

[3] X.-F. Yang, A. Wang, B. Qiao, J. Li, J. Liu, T. Zhang, Acc. Chem. Res. 2013, 46, 1740-1748.

[4] J. Y. Liu, ACS Catal. 2017, 7, 34-59.

[5] S. Mitchell, J. Meurig Thomas, J. Pérez-Ramírez, Catal. Sci. Technol. 2017, 7, 4248-4249.

[6] H. Yan, C. Su, J. Hed, W. Chen, J. Mater. Chem. A 2018, 6, 87938814.

[7] A. Wang, J. Li, T. Zhang, Nat. Rev. Chem. 2018, 2, 65-81.

[8] S. Mitchell, E. Vorobyeva, J. Pérez-Ramírez, Angew. Chem. Int. Ed. 2018, DOI: 10.1002/anie.201806936.

[9] G. S. Parkinson, Unravelling Single Atom Catalysis: The Surface Science Approach, arXiv:1706.09473 [cond-mat.mtrl-sci].

[10] C. Wang, X.-K. Gu, H. Yan, Y. Lin, J. Li, D. Liu, W.-X. Li, J. Lu, ACS Catal. 2017, 7, 887-891.

[11] G.X. Pei, X.Y. Liu, X. Yang, L. Zhang, A. Wang, L. Li, H. Wang, X. Wang, T. Zhang, ACS Catal. 2017, 7, 1491-1500.

[12] H. Yan, H. Cheng, H. Yi, Y. Lin, T. Yao, C. Wang, J. Li, S. Wei, J. Lu, J. Am. Chem. Soc. 2015, 137, 10484-10487.

[13] Z. Zhang, Y. Zhu, H. Asakura, B. Zhang, J. Zhang, M. Zhou, Y. Han, T. Tanaka, A. Wang, T. Zhang, N. Yan, Nat. Commun. 2017, 8, 16100.

[14] S. Sun, G. Zhang, N. Gauquelin, N. Chen, J. Zhou, S. Yang, W. Chen, X. Meng, D. Geng, M. N. Banis, R. Li, S. Ye, S. Knights, G. A. Botton, T.-K. Sham, X. Sun, Sci. Rep. 2013, 3, 1775-1783.

[15] A. Corma, P. Concepcion, M. Boronat, M. Sabater, J. Navas, M. Yacaman, E. Larios, A. Posadas, M. Lopez-Quintela, D. Buceta, E. Mendoza, G. Guilera, A. Mayoral, Nat. Chem. 2013, 5, 775-778.

[16] J. Xie, K. Yin, A. Serov, K. Artyushkova, H. N. Pham, X. Sang, R. R. Unocic, P. Atanassov, A. K. Datye, R. J. Davis, ChemSusChem 2017, 10, 359-362.

[17] M. Pagliaro, F. Meneguzzo, Chem. Eur. J. 2017, 23, 15276-15282.

[18] J. L. Bower, M. C. Christensen, Harv. Bus. Rev. 1995, 73 (1), $43-53$.

[19] X. Zhang, Z. Sun, B. Wang, Y. Tang, L. Nguyen, Y. Li, F. Feng Tao, J. Am. Chem. Soc. 2018, 140, 954-962.

[20] Z. Chen. E. Vorobyeva, S. Mitchell, E. Fako, M.A. Ortuño, N. López, S.M. Collins, P. A. Midgley, S. Richard, G. Vilé, J. Perez-Ramirez, Nature Nanotechnol. 2018, 13, 702-707.

[21] M. Diesendorf, B. Elliston, Renew. Sust. Energ. Rev. 2018, 93, 318330.

[22] M. Pagliaro, A. G. Konstandopoulos, Solar Hydrogen, RSC Publishing, Cambridge: 2012.

[23] For example, state of the art alkaline water electrolysers employing $3.8 \mathrm{kWh}$ to produce $1 \mathrm{Nm}^{3} \mathrm{H}_{2}$ (roughly $90 \mathrm{~g}$ of hydrogen) produced in Europe by NEL Hydrogen. See at the URL: http://nelhydrogen.com/product/electrolysers/.

[24] N. Gallandat, K. Romanowicz, A. Züttel, J. Power Ener. Eng. 2017, 5, 34-49.

[25] H. Fei, J. Dong, M. J. Arellano-Jiménez, G. Ye, N. D. Kim, E. L. G. Samuel, Z. Peng, Z. Zhu, F. Qin, J. Bao, M. J. Yacaman, P. M. Ajayan, D. Chen, J. M. Tour, Nat. Commun. 2015, 6, Article number: 8668.

[26] B. Biebuyck, European Commission's fuel cell and hydrogen joint undertaking, cit. in: J. Harvey, Platinum's days as fuel cell car component may be numbered, Reuters, 23 March 2018. https://uk.reuters.com/article/uk-platinum-fuelcells/platinums-daysas-fuel-cell-car-component-may-be-numbered-idUKKBN1GZ2KO

[27] T. Yoshida, K. Kojima, Toyota Mirai Fuel Cell Vehicle and Progress Toward a Future Hydrogen Society, The Electrochemical Society Interface, Summer 2015, 45-49.

[28] R. Kamai, K. Kamiya, K. Hashimoto, S. Nakanishi, Angew. Chem., Int. Ed. 2016, 55, 13184-13188.
[29] J. Artz, ChemCatChem 2018, 10, 1753-1771.

[30] M. Dhiman, V. Polshettiwar, ChemCatChem 2018, 10, 881-906.

[31] X. Cui, K. Junge, X. Dai, C. Kreyenschulte, M.-M. Pohl, S. Wohlrab, F. Shi, A. Brückner, M. Beller, ACS Cent. Sci. 2017, 3, 580-585.

[32] Prof. M. Beller, Rostock University, personal correspondence with M.P. (June 2018).

[33] For example, in the room temperature Ullmann coupling reaction of aryl chlorides mediated by AuPd alloyed nanoparticles supported on nitrogen-rich mesoporous carbon: B. Karimi, H. Barzegar, H. Vali, $\mathrm{Au}-\mathrm{Pd}$ bimetallic nanoparticles supported on a high nitrogen-rich ordered mesoporous carbon as an efficient catalyst for room temperature Ullmann coupling of aryl chlorides in aqueous media, Chem. Commun. 2018, 54, 7155-7158.

[34] R. Lang, T. Li, D. Matsumura, S. Miao, Y. Ren, Y.-T. Cui, Y. Tan, B. Qiao, L. Li, A. Wang, X. Wang, T. Zhang, Angew. Chem. Int. Ed. 2016, 55, 16054-16058.

[35] R. Ciriminna, E. Falletta, C. Della Pina, J. H. Teles, M. Pagliaro, Angew. Chem. Int. Ed. 2016, 55, 14210-14217.

[36] Nel ASA, Nel Hydrogen Electrolyser, Our world of electrolysers, Case studies, Illovo Sugar SA (Ltd), 2017. http://nelhydrogen.com/assets/uploads/2017/01/Nel_Electrolyser_ brochure.pdf

[37] K. R. Paton, E. Varrla, C. Backes, R.J. Smith, U. Khan, A. O'Neill, C. Boland, M. Lotya, O. M. Istrate, P. King, T. Higgins, S. Barwich, P. May, P. Puczkarski, I. Ahmed, M. Moebius, H. Pettersson, E. Long, J. Coelho, S. E. O'Brien, E. K. McGuire, B. Mendoza Sanchez, G. S. Duesberg, N. McEvoy, T. J. Pennycook, C. Downing, A. Crossley, V. Nicolosi, J. N. Coleman, Nat. Mater. 2014, 13 , 624630

[38] R. Ciriminna, N. Zhang, M.-Q. Yang, F. Meneguzzo, Y.-J. Xu, M. Pagliaro, Chem. Commun. 2015, 51, 7090-7095.

[39] Prof. James M. Tour, Rice University, personal communication with M.P. (June 2018).

[40] S. S. Zalesskiy, V. P. Ananikov, Organometallics 2012, 31, 23022309.

[41] M. Pagliaro, F. Meneguzzo, J. Phys. Energy 2018, 1, xx (in press). 
